\title{
The Indian Ocean: The Region of Highest Skill Worldwide in Decadal Climate Prediction*
}

\author{
VIRGINIE GUEMAS \\ Institut Català de Ciències del Clima, Barcelona, Spain
}

\section{SUSANNA CORTI}

European Centre for Medium-Range Weather Forecasts, Reading, United Kingdom, and Istituto di Scienze dell'Atmosfera e del Clima, Consiglio Nazionale delle Riceche, Bologna, Italy

\section{J. GARCÍA-SERRANO}

Institut Català de Ciències del Clima, Barcelona, Spain

\section{F. J. DOBLAS-REYES}

Institut Català de Ciències del Clima and Instituciò Catalana de Recerca i Estudis Avancats, Barcelona, Spain

\author{
Magdalena Balmaseda And Linus Magnusson
}

European Centre for Medium-Range Weather Forecasts, Reading, United Kingdom

(Manuscript received 18 January 2012, in final form 22 June 2012)

\begin{abstract}
The Indian Ocean stands out as the region where the state-of-the-art decadal climate predictions of sea surface temperature (SST) perform the best worldwide for forecast times ranging from the second to the ninth year, according to correlation and root-mean-square error (RMSE) scores. This paper investigates the reasons for this high skill by assessing the contributions from the initial conditions, greenhouse gases, solar activity, and volcanic aerosols. The comparison between the SST correlation skill in uninitialized historical simulations and hindcasts initialized from estimates of the observed climate state shows that the high Indian Ocean skill is largely explained by the varying radiative forcings, the latter finding being supported by a set of additional sensitivity experiments. The long-term warming trend is the primary contributor to the high skill, though not the only one. Volcanic aerosols bring additional skill in this region as shown by the comparison between initialized hindcasts taking into account or not the effect of volcanic stratospheric aerosols and by the drop in skill when filtering out their effect in hindcasts that take them into account. Indeed, the Indian Ocean is shown to be the region where the ratio of the internally generated over the externally forced variability is the lowest, where the amplitude of the internal variability has been estimated by removing the effect of long-term warming trend and volcanic aerosols by a multiple least squares linear regression on observed SSTs.
\end{abstract}

\footnotetext{
* Supplemental information related to this paper is available at the Journals Online website: http://dx.doi.org/10.1175/JCLI-D-1200049.s1.

Corresponding author address: Virginie Guemas, Institut Català de Ciències del Clima, Carrer Trueta, 203, 08005 Barcelona, Spain. E-mail:vguemas@ic3.cat
}

\section{Introduction}

The newborn exercise of near-term climate prediction, also termed decadal prediction (Smith et al. 2007; Keenlyside et al. 2008; Pohlmann et al. 2009; Meehl et al. 2009; Mochizuki et al. 2010; Murphy et al. 2010; DoblasReyes et al. 2011), offers a great opportunity to revisit the available observational datasets from a new angle 
and compare further the physical processes represented in our models against these observational datasets. At the edge between seasonal forecasting and climate change projections, near-term climate predictions exploit both the predictability of the climate system arising from the initial-condition information and from the changes in radiative external forcings (Hawkins and Sutton 2009b). This exercise demonstrates the extent of our understanding and ability to predict a posteriori the climate system history over the last decades. Within the context of this decadal prediction exercise, we focus in this article on the predictability of Indian Ocean sea surface temperatures (SSTs), which have been shown to significantly influence the eastern African (Birkett et al. 1999; Saji et al. 1999), Australian (Smith et al. 2000; Ashok et al. 2003), and Indian monsoon (Ashok et al. 2001) rainfall, and more remotely the Euro-Atlantic sector (Hoerling et al. 2001; Bader and Latif 2005; Sanchez-Gomez et al. 2008). The Indian basin has been pointed out as one of the most sensitive regions to anthropogenic greenhouse gas warming (Deser et al. 2010a,b), which favors a large potential predictability of its externally forced climate signal (Boer 2011).

\section{Data and methods}

\section{a. The ensemble of decadal predictions}

The subsequent analyses rely on a unique set of four ensembles of hindcasts, the characteristics of which are summarized in Table 1.

- The first one comprises the contributions to phase 5 of the Coupled Model Intercomparison Project (CMIP5; Taylor et al. 2012) produced with the third climate configuration of the Hadley Center Coupled Model (HadCM3; Gordon et al. 2000; Pope et al. 2000), the Meteorological Research Institute Coupled General Circulation Model version 3 (MRI-CGCM3; Yukimoto et al. 2001), the Model for Interdisciplinary Research on Climate versions 4 and 5 (MIROC4 and MIROC5; Hasumi and Emori 2004) and the EC-Earth v2 (Hazeleger et al. 2010; Du et al. 2012) coupled climate models with respectively $10,9,3,6$, and 5 members. These contributions consist of 10 -yr-long hindcasts initialized from estimates of the observed climate states every 5 years over the period 1960-2005. These hindcasts take into account the changes in external forcings such as greenhouse gases, solar activity, stratospheric aerosols associated with volcanic eruptions, and anthropogenic aerosols. This multimodel ensemble will be referred to as CMIP5 Init in the following. A sister ensemble has been built from the historical simulations and the first years of the climate change projections following the Representative Concentration Pathway 4.5 (RCP4.5) Fifth Assessment Report (AR5) scenario run with the same models. The simulated natural variability does not follow the history of the observed one in this second experiment. The ensembles comprise respectively 10,1,3,1, and 3 members for the HadCM3, the MRI-CGCM3, the MIROC4, the MIROC5 and the EC-Earth v2 models. This multimodel ensemble of so-called uninitialized hindcasts will be referred to as CMIP5 NoInit in the following. With the EC-Earth v2 model, the CMIP5 Init hindcasts have been extended to one start date every year over the period 1960-2005 with five members. Those additional hindcasts will be used to illustrate hindcasted time series of Indian Ocean SST in the following but they will not be included in the CMIP5 Init ensemble.

- The second is the perturbed-parameter nine-member ensemble known as Met Office Decadal Climate Prediction System (DePreSys) (Smith et al. 2007, 2010), produced with the HadCM3 model (Hawkins and Sutton 2009a; Gordon et al. 2000) and eight variants of this model (Murphy et al. 2004). Ten-year-long hindcasts were started every year from 1960 to 2005 on 1 November (Robson 2010). These hindcasts take into account the changes in external forcings such as greenhouse gases, solar activity, and anthropogenic aerosols, but the effects of stratospheric aerosols are only accounted for when the volcanic eruption occurs prior to the initialization and its effect is damped along the hindcast. This multimodel ensemble will be referred to as DePreSys Init in the following. A sister experiment has been run with the same models taking into account the effect of the same external forcings as in DePreSys Init but "uninitialized." This multimodel ensemble will be referred to as DePreSys NoInit in the following.

- The third one comprises 27 members started every five years from 1960 to 2005, on 1 November, and is produced by the European Center for Medium-Range Weather Forecasts (ECMWF) (Magnusson et al. 2011; Molteni et al. 2011). The global coupled model comprises the Integrated Forecast System (IFS) atmospheric component (http://www.ecmwf.int/research/ifsdocs/ CY36r1/index.html) with a horizontal truncation of TL159 and 91 vertical levels and the Nucleus for European Modelling of the Ocean (NEMO) V3.0 ocean component (Madec 2008) in the ORCA1configuration and 42 levels. The sea ice is specified along the simulations as time series of observations built up by sampling the previous 5 years. Sea ice persists in the initial sea ice analysis for the first 10 days and then a transition toward the specified ice derived from the previous 5 years is applied over the next 20 days. The 
TABLE 1. Summary table of the ensembles of decadal hindcasts used in this article. The second column provides the list of models comprised in the ensemble. The third column provides the frequency of the start dates. The fourth and fifth columns indicate respectively if the ensembles comprise some initialized or uninitialized subensembles and if they comprise subensembles with or without volcanoes. The sixth column indicates if the anthropogenic aerosols are taken into account or not. More details are provided in section 2. Models included under ENSEMBLES are the Centre National de Recherches Météorologiques Coupled Global Climate Model, version 3 (CNRM-CM3), Hadley Centre Global Environmental Model version 2 (HadGEM2), the ECMWF forecast system version 3, and ECHAM5-Max Planck Insitute Global Ocean/Sea Ice Model version 1 (ECHAM5-MPI-OM1).

\begin{tabular}{|c|c|c|c|c|c|}
\hline Ensemble name & Models & $\begin{array}{l}\text { Start date } \\
\text { frequency }\end{array}$ & Init/NoInit & Vol/NoVol & Anthropo. aero. \\
\hline \multirow[t]{4}{*}{ CMIP5 } & \multirow{4}{*}{$\begin{array}{l}\text { HadCM3, MRI-CGCM3, MIROC4, } \\
\text { MIROC5, EC-Earth v2 }\end{array}$} & \multirow[t]{4}{*}{$5 \mathrm{yr}$} & \multirow[t]{2}{*}{ Init } & Vol & Yes \\
\hline & & & & - & - \\
\hline & & & \multirow[t]{2}{*}{ NoInit } & Vol & Yes \\
\hline & & & & - & - \\
\hline \multirow[t]{4}{*}{ DePreSys } & \multirow[t]{4}{*}{ Nine variants of HadCM3 } & \multirow[t]{4}{*}{$1 \mathrm{yr}$} & \multirow[t]{2}{*}{ Init } & - & - \\
\hline & & & & NoVol & Yes \\
\hline & & & \multirow[t]{2}{*}{ NoInit } & - & - \\
\hline & & & & NoVol & Yes \\
\hline \multirow[t]{3}{*}{ ECMWF Set1 } & \multirow[t]{3}{*}{ ECMWF forecast system with 27 members } & \multirow[t]{3}{*}{$5 \mathrm{yr}$} & \multirow[t]{2}{*}{ Init } & Vol & No \\
\hline & & & & NoVol & No \\
\hline & & & - & - & - \\
\hline \multirow[t]{3}{*}{ ENSEMBLES } & \multirow{3}{*}{$\begin{array}{l}\text { CNRM-CM3, ECMWF-S3, HadGEM2, } \\
\text { ECHAM5/MPI-OM1 }\end{array}$} & \multirow[t]{3}{*}{$5 \mathrm{yr}$} & \multirow[t]{2}{*}{ Init } & - & - \\
\hline & & & & NoVol & Partly \\
\hline & & & - & - & \\
\hline
\end{tabular}

ocean is initialized from NEMO variational data assimilation system (NEMOVAR)-Comprehensive Modeling of the Earth System for Better Climate Prediction and Projection reanalysis (COMBINE; Balmaseda et al. 2010), the atmospheric land component from the 40-yr ECMWF Re-Analysis (ERA-40; Uppala et al. 2004) for the period 1960 to 1985 and the ECMWF Interim ReAnalysis (ERA-Interim; Dee et al. 2011) for the remaining start dates. These hindcasts take into account the changes in external forcings such as greenhouse gases and solar activity. Six members take into account the effect of stratospheric aerosols and twenty-one members do not. This ensemble comprising twenty-seven members will be referred to as ECMWF Set 1 in the following. Sensitivity experiments have also been run with the ECMWF forecast system, comprising the Louvain-la-Neuve Sea Ice Model version 2 (LIM2; Fichefet and Maqueda 1997; Goosse and Fichefet 1999) this time. They consist of 10-yr-long five-member hindcasts initialized in 1965 and 1995, but with estimates of the 1995 and 1965 observed climate states respectively, and 10-yr-long five-member hindcasts initialized in 1965 and 1995, but using the external forcings of 1995-2005 and 1965-75 respectively, with the rest of the experimental design corresponding to ECMWF Set 1 . This set of sensitivity experiments will be referred to as ECMWF Set 2 in the following.
- The fourth one comprises the contributions to the EU-funded project ENSEMBLES (Doblas-Reyes et al. 2010) from four different general circulation models. The experimental setup consists of 10-yr-long three-member hindcasts initialized once every five years over the period 1960-2005, on 1 November, from an estimate of the observed climate state. These hindcasts take into account the changes in external forcings such as greenhouse gases and solar activity for the four models and in anthropogenic aerosols for three of the four models. The stratospheric aerosols are not accounted for except in one contribution where it is done as in the DePreSys ensemble.

\section{b. Diagnostics and significance level}

We focus our analysis on the sea surface temperature and compare the predicted SST to the National Oceanic and Atmospheric Administration (NOAA) Extended Reconstructed SST v3b dataset (hereafter ERSST) (Smith et al. 2008). The modeled or observed climatology is defined as a function of the forecast time (i.e., of the predicted month) by averaging the predicted SST across the start dates taking into account only the predicted values for which observations are available at the corresponding date. The model climatologies obtained in such a way are then subtracted from each raw hindcast 


\section{a) Forecast times : 2-5 years}

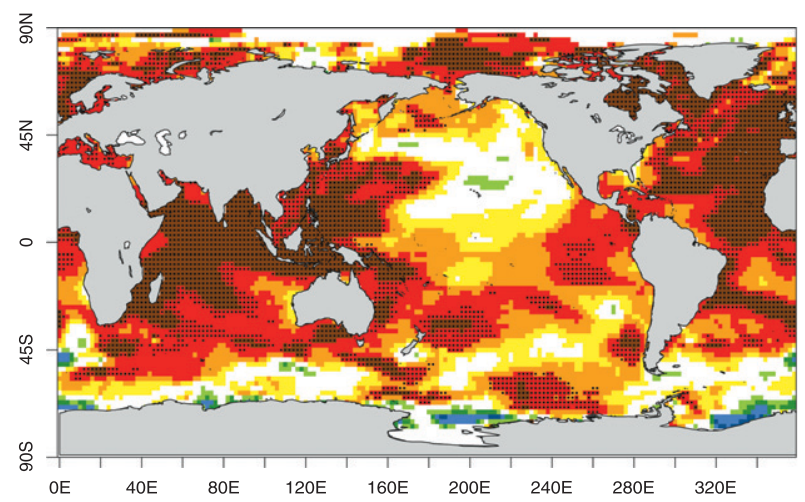

\section{b) Forecast times : 6-9 years}

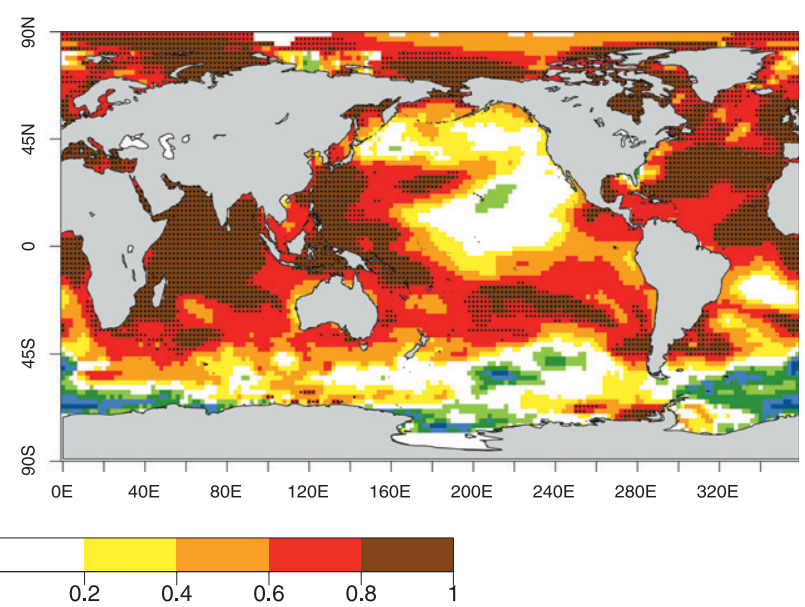

c) Correlation

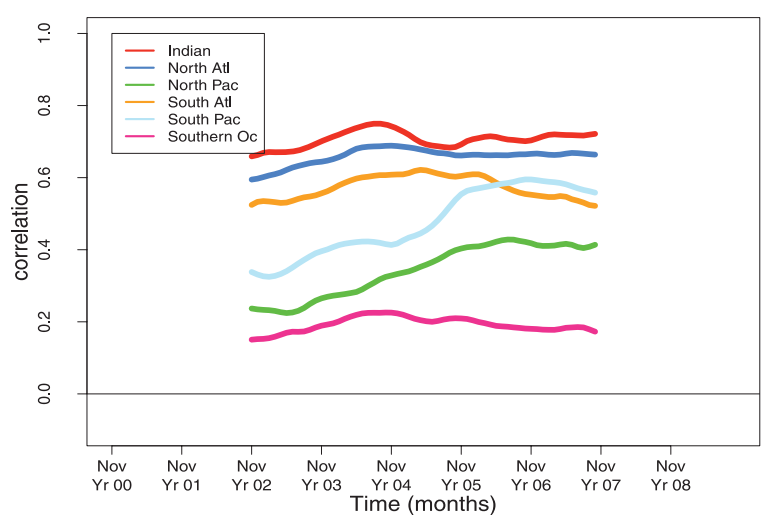

d) Root Mean Square Error

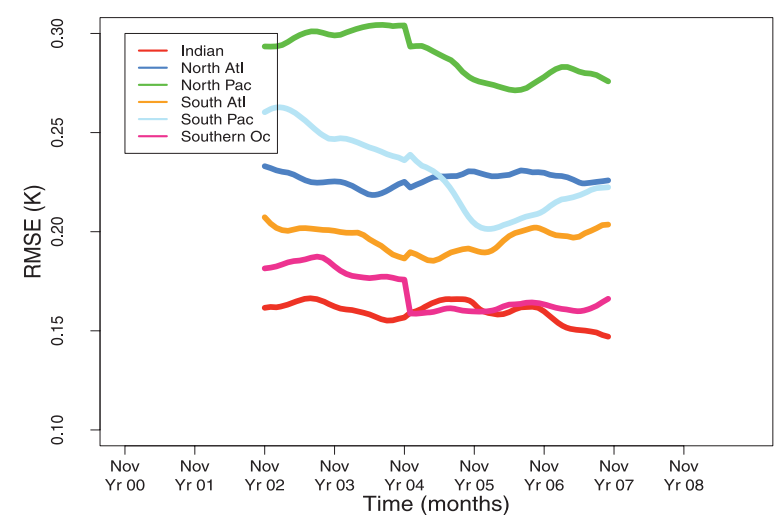

FIG. 1. (a),(b) Correlation between the ensemble-mean predicted and ERSST sea surface temperature anomalies $\left({ }^{\circ} \mathrm{C}\right)$ averaged across the forecast times ranging from 2 to 5 and 6 to 9 years in the CMIP5 Init decadal hindcasts. The black dotted regions indicate where the correlation is significant to the $95 \%$ level according to a $t$ test that accounts for the autocorrelation of the data. (c),(d) Skill scores computed against the ERSST data across the start dates, longitude, and latitude dimensions simultaneously after applying a 4-yr running mean: correlation skill and RMSE for the Indian $\left(40^{\circ} \mathrm{S}-30^{\circ} \mathrm{N}, 20^{\circ}-120^{\circ} \mathrm{E}\right)$, North Atlantic $\left(0^{\circ}-65^{\circ} \mathrm{N}, 100^{\circ} \mathrm{W}-40^{\circ} \mathrm{E}\right)$, North Pacific $\left(0^{\circ}-65^{\circ} \mathrm{N}, 100^{\circ}-260^{\circ} \mathrm{E}\right)$, South Atlantic $\left(45^{\circ} \mathrm{S}-0^{\circ}, 75^{\circ} \mathrm{W}-20^{\circ} \mathrm{E}\right)$, South Pacific $\left(45^{\circ} \mathrm{S}-0^{\circ}, 120^{\circ}-285^{\circ} \mathrm{E}\right)$, and Southern $\left(70^{\circ}-45^{\circ} \mathrm{S}\right)$ Oceans in CMIP5 Init hindcasts.

to obtain anomalies over the whole predicted period. The same method is applied to the observations to obtain anomalies over the whole observational period. The obtained anomalies are known as "per pair" anomalies (Garcia-Serrano and Doblas-Reyes 2012). Debiasing a hindcast consists of subtracting the model climatology and adding the observed one to this hindcast.

The SST skill is assessed either using the anomaly correlation coefficient or using the root-mean-square error (RMSE). The significance level for the correlation skill is computed via a one-sided Student's $t$ test, which takes into account the autocorrelation of the time series (Zieba 1995; VonStorch and Zwiers 1999), except for the ECMWF experiments in which it is computed by a bootstrap test.

\section{A high SST skill in the Indian Ocean: Contribution of the external forcings}

From the global maps of SST correlation score in CMIP5 Init multimodel ensemble (Figs. 1a,b), the Indian Ocean stands as one of the regions of highest skill worldwide both at forecast times of 2 to 5 years (Fig. 1a) and 6 to 9 years (Fig. 1b). The particularly large SST skill in the Indian basin is robust among the four ensembles used in this study and described in the section 2 [see Fig. S1 (in the supplement) for forecast times 2 to 5 years and Fig. S3 for forecast times 6 to 9 years], as well as against the score chosen (see Figs. S2 and S4 for RMSE maps). To quantify the performances of CMIP5 Init hindcasts in the different basins, we compute the 
correlation (Fig. 1c) and RMSE (Fig. 1d) of the predicted against observed SST anomalies across the longitude, latitude, and start dates, for the Indian $\left(40^{\circ} \mathrm{S}-30^{\circ} \mathrm{N}, 20^{\circ}-\right.$ $\left.120^{\circ} \mathrm{E}\right)$, North Atlantic $\left(0^{\circ}-65^{\circ} \mathrm{N}, 100^{\circ} \mathrm{W}-40^{\circ} \mathrm{E}\right)$, North
Pacific $\left(0^{\circ}-65^{\circ} \mathrm{N}, 100^{\circ}-260^{\circ} \mathrm{E}\right)$, South Atlantic $\left(45^{\circ} \mathrm{S}-0^{\circ}\right.$, $\left.75^{\circ} \mathrm{W}-20^{\circ} \mathrm{E}\right)$, South Pacific $\left(45^{\circ} \mathrm{S}-0^{\circ}, 120^{\circ}-285^{\circ} \mathrm{E}\right)$, and Southern $\left(70^{\circ}-45^{\circ} \mathrm{S}\right)$ Oceans after applying a 4-yr running mean:

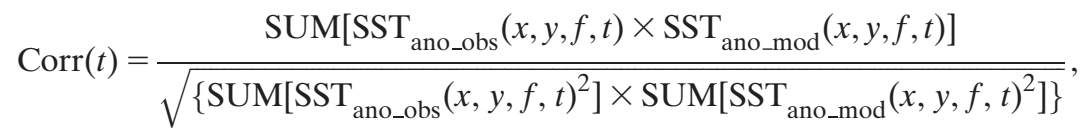

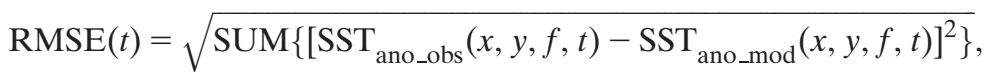

where $\operatorname{SUM}()=\sum_{x=\text { lonmin }}^{x=\text { lonmax }} \sum_{y=\text { latmin }}^{y=\operatorname{latmax}} \sum_{f=\text { forecast1 } 1}^{f=\text { forecasto }} \mathrm{SST}_{\text {ano_obs }}$ and $\mathrm{SST}_{\text {ano_mod }}$ stand for the observed and modeled perpair SST anomalies computed as described in section 2; lonmin, lonmax, latmin, and latmax correspond to the geographical limits defined for a given region; forecast1 and forecast 10 correspond to the first and tenth forecast, respectively; and $t$ is the forecast time. Those scores quantify the ability of CMIP5 Init hindcasts to reproduce the spatial patterns rather than the basin-averaged SST anomalies as a function of the forecast time. The Indian basin stands as the region of highest correlation all along the forecast, followed closely by the North Atlantic basin. In terms of RMSE (Fig. 1d), the Southern Ocean is the only one performing slightly better than the Indian Ocean during the fifth year. However, the weakness of the SST anomalies to be predicted in this region explains its low RMSE, but the forecast systems do not properly reproduce these anomaly patterns, as can be seen with its correlation, which is the lowest among all basins. Accounting for both the RMSE and the correlation scores, the Indian basin thus appears as the region where the state-of-the-art decadal SST predictions perform the best worldwide.

The Indian Ocean maps of SST correlation score in the CMIP5 (Figs. 2a,b) and DePreSys Init (Figs. 2c,d) (left column) multimodel ensembles bear strong similarities to the CMIP5 and DePreSys NoInit ones (middle column), respectively, for forecast times of 2 to 5 years (Figs. 2a,c) and 6 to 9 years (Figs. 2b,d). The left panels of Fig. 2 are a zoomed-in view of the Indian Ocean from Figs. 1a,b Figs. S1b and S3b. The Indian Ocean maps of the difference in SST skill between the CMIP5 Init and CMIP5 NoInit multimodel ensembles on one side and the DePresys Init and DePreSys NoInit multimodel ensembles on the other side (right column) give consistent negligible and not significant (at the $95 \%$ significance level) values for forecast times of 2-5 and 6-9 years. Those maps indicate the added value of the forecast system initialization. A small fraction of the skill could be associated with the initial-condition information in the $20^{\circ}-40^{\circ} \mathrm{S}$ latitude band, in particular near Australia and Madagascar. However, the differences in correlation are not significant in those areas. The significance level is high because of the small amount of independent data. Indeed, even when using hindcasts with yearly start dates, that is 46 hindcasts, as in the DePreSys ensemble, two consecutive hindcasts cannot be considered as independent. The number of effective independent data at the grid point level ranges between 10 and 20 applying the formula described in Zieba (1995) and VonStorch and Zwiers (1999). Such an attribution of added value of the initial-condition information near Australia or Madagascar would require more independent hindcasts by lengthening the reforecasted period. We conclude at this stage that, from Fig. 2, the high Indian Ocean skill appears as largely attributable to the varying radiative forcings.

This conclusion is illustrated by the ECMWF Set 2 sensitivity experiments (Fig. 3). The Indian Ocean $\left(40^{\circ} \mathrm{S}-30^{\circ} \mathrm{N}, 20^{\circ}-120^{\circ} \mathrm{E}\right) \mathrm{SST}$ from predictions initialized in 1965 (Fig. 3a) and 1995 (Fig. 3b) from estimates of the observed climate state of years 1995 and 1965, respectively (red lines and orange shading), show little difference with those from hindcasts initialized with the contemporaneous climate state (blue lines and gray shading). Although they are initially $0.3^{\circ} \mathrm{C}$ apart from one another, their ensemble-means converge immediately and then undergo similar oscillations while their ensemble spreads strongly overlap. This result illustrates the minor role of the initial-condition information on the Indian Ocean surface temperature in a particular example in which one of the selected initial states is $0.3^{\circ} \mathrm{C}$ warmer than the other one in the Indian Ocean. On the contrary, the Indian Ocean $\left(40^{\circ}-30^{\circ} \mathrm{N}\right.$, $\left.20^{\circ}-120^{\circ} \mathrm{E}\right) \mathrm{SSTs}$ from predictions initialized in 1965 (Fig. 3c) and 1995 (Fig. 3d) but in which the external forcings of the 1995-2005 period and 1965-75 period respectively are applied (red lines and orange shading) show an initial drift toward a too warm and toocold state, respectively. After a 2-yr adjustment, the 


\section{a) CMIP5. 2-5 years}
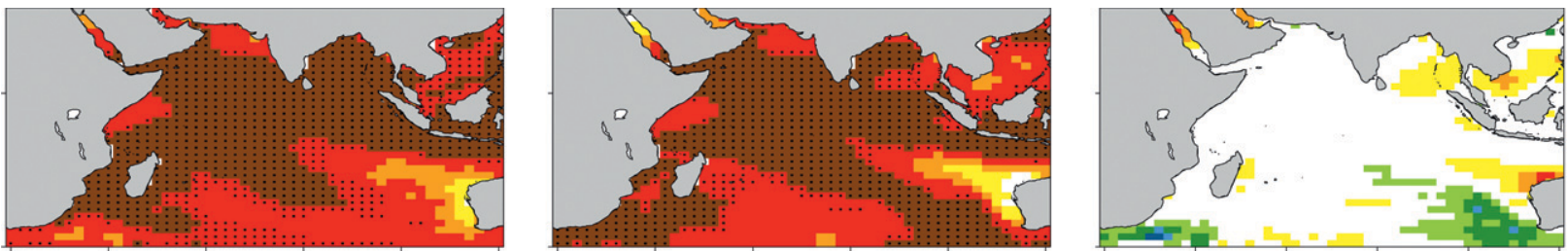

b) CMIP5. 6-9 years
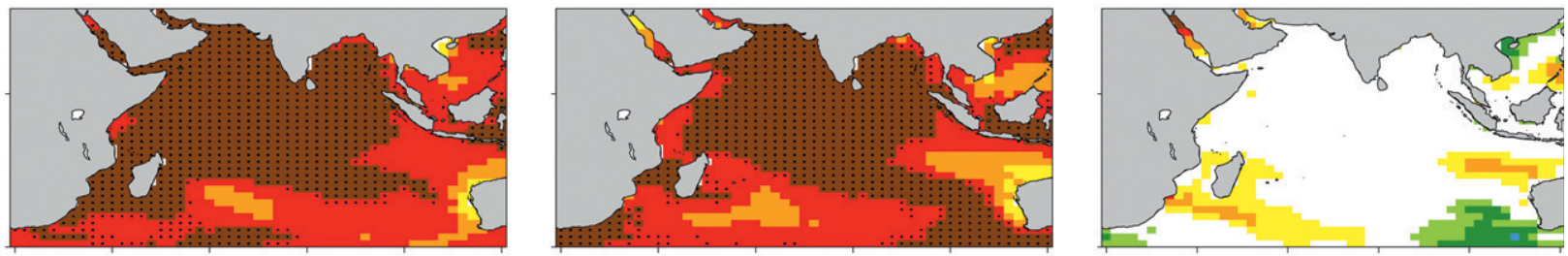

\section{c) DePresys. 2-5 years}
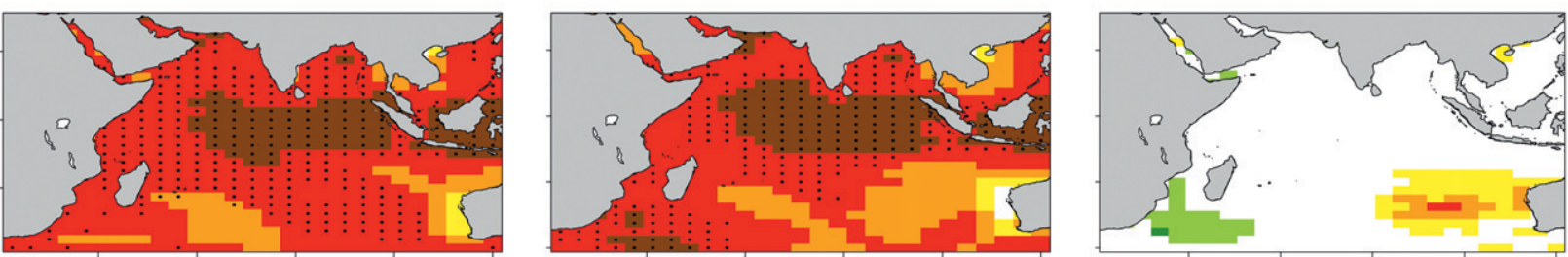

\section{d) DePreSys. 6-9 years}
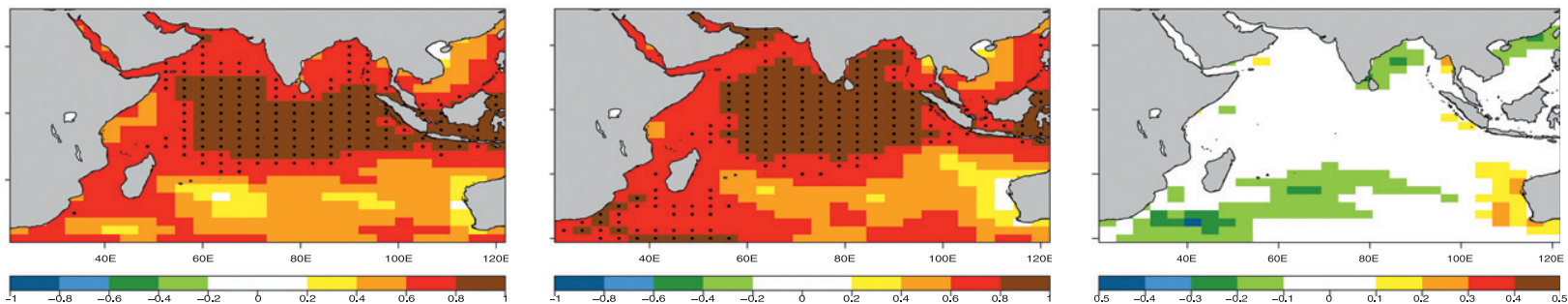

FIG. 2. (left),(middle) Correlation between the ensemble-mean predicted and ERSST sea surface temperature anomalies averaged across the forecast times ranging from (a),(c) 2 to 5 and (b),(d) 6 to 9 years in the (a),(b) CMIP5 and (c),(d) DePreSys decadal hindcasts. The left and middle columns correspond respectively to the Init and NoInit ensembles. (right) Difference in correlation between the (a),(b) CMIP5 Init (5-yr start dates) decadal hindcasts and the CMIP5 NoInit historical simulations and between the (c),(d) DePreSys Init decadal hindcasts (yearly start dates) and DePreSys NoInit historical simulations, for the forecast times ranging from (a),(c) 2 to 5 years and (b), (d) 6 to 9 years. The black dotted regions indicate where the correlation or difference in correlation is significant at the $95 \%$ level according to a $t$ test that accounts for the autocorrelation of the data.

distance between the observed SST and the prediction envelop can reach $0.5^{\circ} \mathrm{C}$ and the distance between the control (blue lines and gray shading) and sensitivity experiment ensemble-mean ranges between $0.15^{\circ}$ and $0.6^{\circ} \mathrm{C}$ with very few overlapping of their ensemble ranges. The control (blue lines) experiments follow approximately the reanalyzed SST (in black) after bias correction while the sensitivity experiments (red lines) are strongly biased. Those sensitivity experiments illustrate the large impact of the varying radiative forcings on the Indian Ocean surface temperature on a particular example in which the selected external forcings are 30 years apart. The relative importance of the external forcing and the initial conditions on the SST signal is quantified by its RMSE (Figs. 3e,f) in those sensitivity experiments. While the RMSE is barely modified by a change in the initial conditions (solid red) compared to the control experiment (solid blue), at an approximate level of $0.1^{\circ}-0.3^{\circ} \mathrm{C}$ (i.e., close to the CMIP5 average RMSE in the Indian Ocean we estimated in Fig. 1d) the RMSE is well above 
a) 1965-1975 hindcast

\section{5 versus 1995 initial conditions}

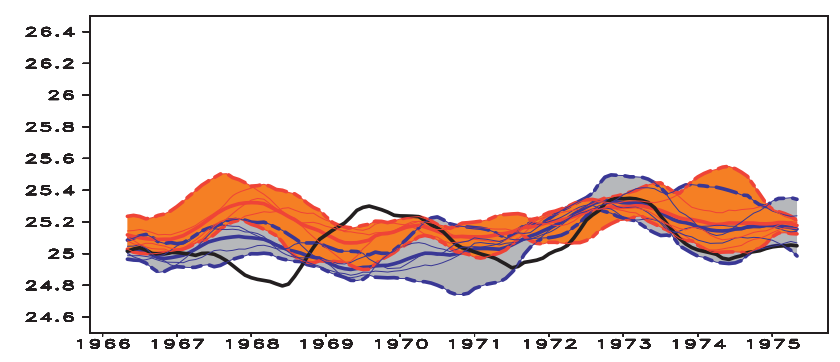

c) 1965-1975 hindcast

1965 versus 1995 forcing

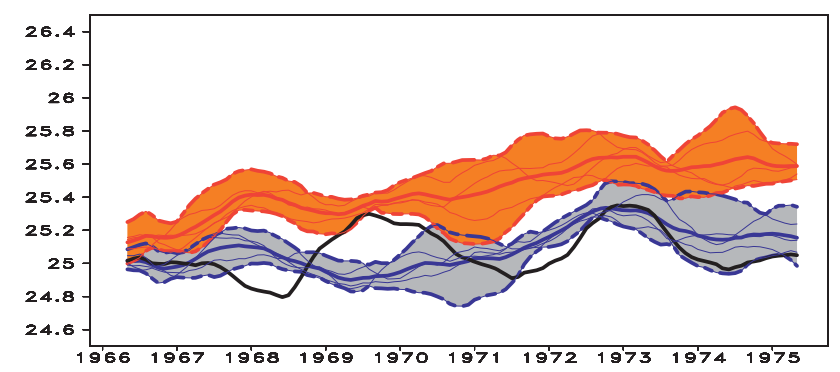

e) 1965-1975 hindcast

1995 forcing vs initial conditions

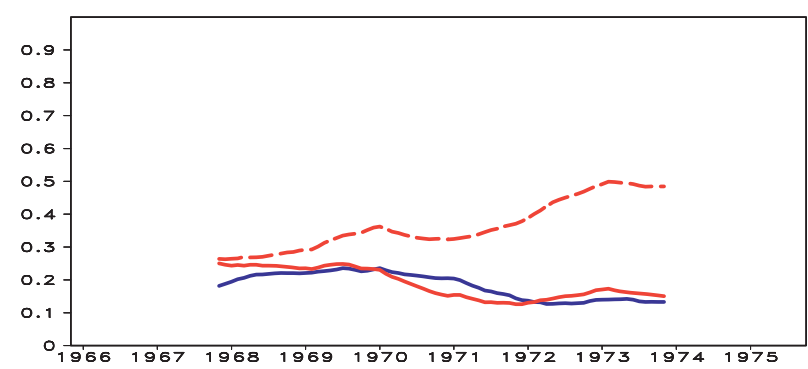

b) 1995-2005 hindcast 1995 versus 1965 initial conditions

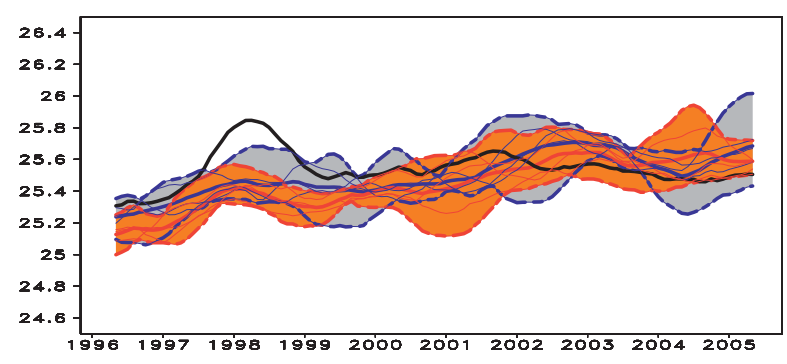

d) 1995-2005 hindcast 1995 versus 1965 forcing

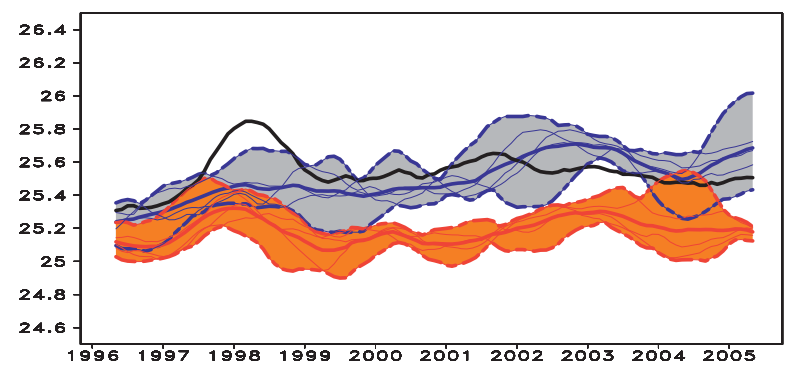

f) 1995-2005 hindcast 1965 forcing vs initial conditions

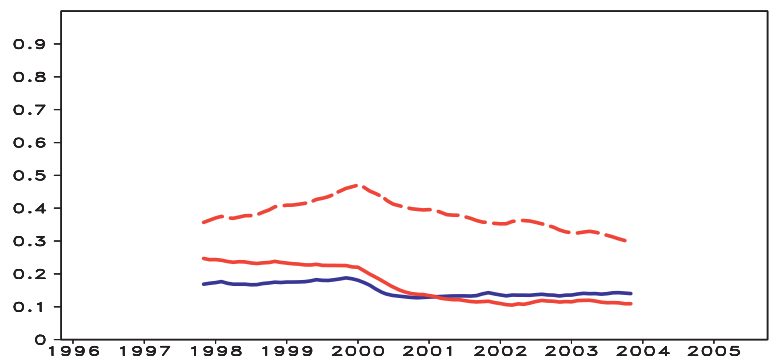

FIG. 3. (a),(b) and (c),(d) Sea surface temperatures averaged in the Indian Ocean $\left(40^{\circ} \mathrm{S}-30^{\circ} \mathrm{N}, 20^{\circ}-120^{\circ} \mathrm{E}\right)$ and smoothed out with a 12-month running mean. ECMWF set 2 after bias correction are in color, and in black are (a),(c) ERA-40 and (b),(d) ERA-Interim. Specifically, blue represents control experiments and red represents sensitivity experiments as follows: (a) 1965-75 external forcing with 1965 (blue) and 1995 (red) initial conditions; (b) 1995-2005 external forcing with 1965 (red) and 1995 (blue) initial conditions; (c) 1965-75 (blue) and 1995-2005 (red) external forcing with 1965 initial conditions; (d) 1965-75 (red) and 1995-2005 (blue) external forcing with 1995 initial conditions. The gray (control experiment) and orange (sensitivity experiment) shading indicates the maximum-minimum envelope across the five ensemble members. (e),(f) RMSEs in the control experiment (blue) and in the sensitivity experiment to the initial conditions (red solid) and to the external forcing (red dashed) after smoothing out the SST with a 4-yr running mean for the hindcast initialized in (e) 1965 and (f) 1995.

that level (between 0.3 and $0.5^{\circ} \mathrm{C}$ ) in the sensitivity experiment to the external forcing (dashed red).

\section{A substantial contribution of the volcanic eruptions to the Indian Ocean SST skill}

When referring to "external forcings," one expects the role of the increasing concentration of greenhouse gases to play a major role in the Indian Ocean surface temperature. Figure 4a shows the Indian Ocean maps of SST correlation after filtering out the anthropogenic greenhouse gas warming effect in the CMIP5 Init multimodel ensemble by a least squares linear regression of the gridpoint SST time series onto the base-2 logarithm of the Mauna Loa $\mathrm{CO}_{2}$ concentration. This figure suggests that the anthropogenic greenhouse gas warming is 
a) $\mathrm{CO} 2$ effect

filtered out by linear regression

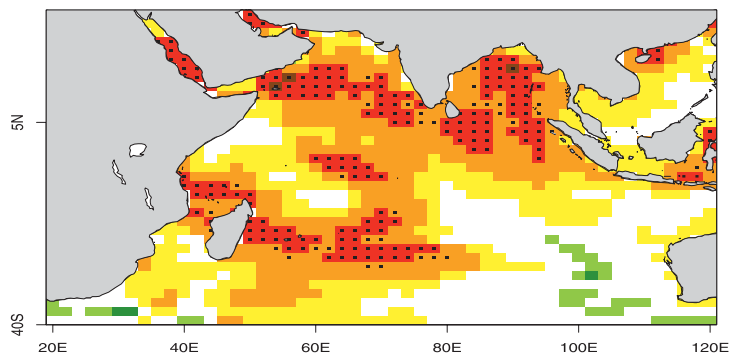

c) $\mathrm{CO} 2+$ volcanic eruptions

filtered out by multiple linear regression

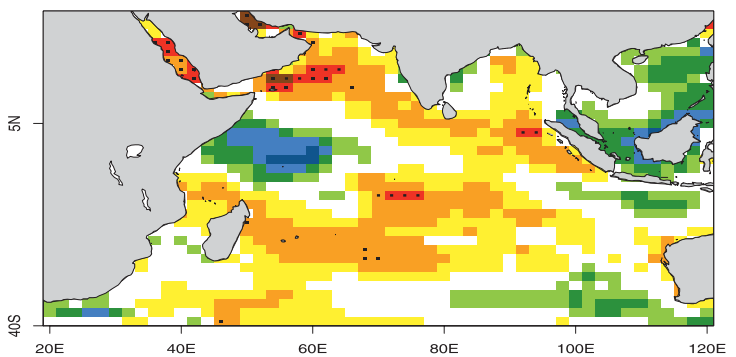

b) $\mathrm{CO} 2+$ Solar activity

filtered out by multiple linear regression

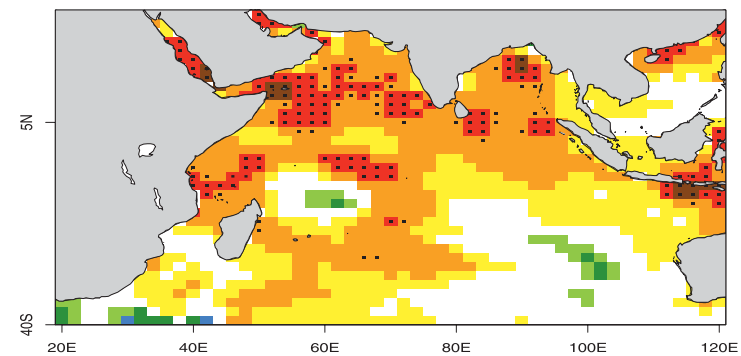

d) $\mathrm{CO} 2+$ Solar + Volcanoes

filtered out by multiple linear regression

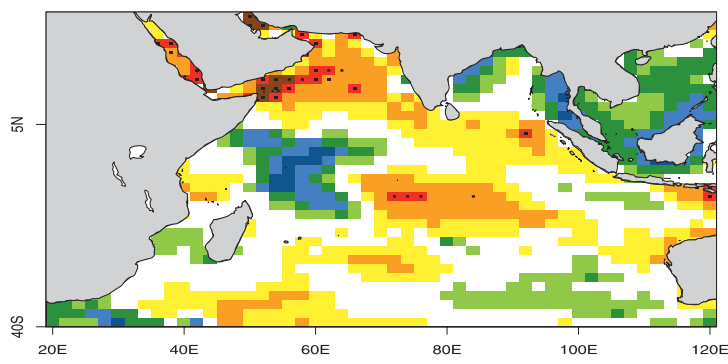

e) $\mathrm{CO} 2+$ volcanic eruptions

filtered out by multiple linear regression

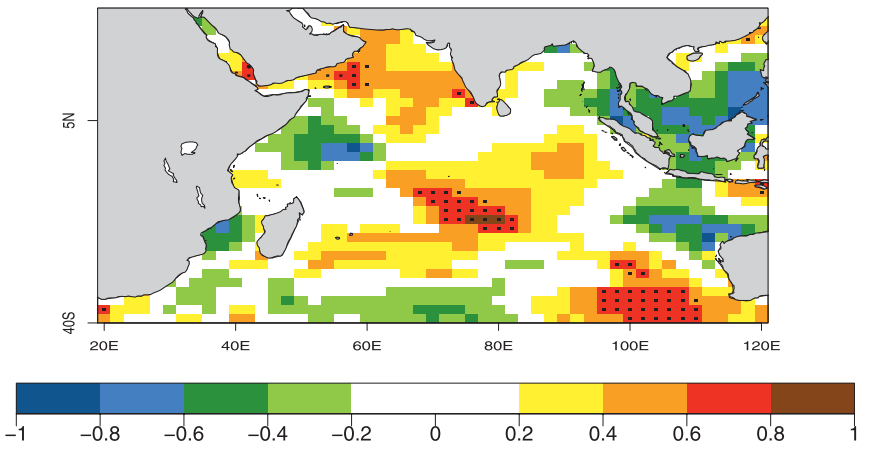

FIG. 4. Correlation between the ensemble-mean predicted and ERSST sea surface temperature anomalies averaged across the forecast times ranging from 2 to 5 years in the (a)-(d) CMIP5 Init decadal hindcasts and (e) CMIP5 NoInit historical simulations: (a) after filtering out the anthropogenic greenhouse gas warming effect by a regression onto the base- 2 logarithm of the Mauna Loa $\mathrm{CO}_{2}$ concentration, (b) after filtering out the anthropogenic greenhouse gas warming effect and the solar activity variation effect by a multiple linear regression onto the base-2 logarithm of the Mauna Loa $\mathrm{CO}_{2}$ concentration and the total solar irradiance, (c),(e) after filtering out the anthropogenic greenhouse gas warming effect and the volcanic eruption effect by a multiple linear regression onto the base-2 logarithm of the Mauna Loa $\mathrm{CO}_{2}$ concentration and stratospheric optical thickness at $550 \mathrm{~nm}$, and (d) after filtering out the anthropogenic greenhouse gas warming, the solar activity variation and the volcanic eruption effects by a multiple linear regression. The black dotted regions indicate where the correlation is significant at the $95 \%$ level.

not the only driver of the Indian Ocean SST skill, as positive correlation skill remains in most of the basin after filtering out this effect: above 0.4 over $50 \%$ of the basin, significant over $20 \%$ of the area, and peaking at 0.9 at some points. In the following, the anthropogenic greenhouse gas warming effect has been filtered out to analyze the other potential contributions to the skill. Indeed, as the skill is very large in this region, filtering out the primary cause for the high skill allows us to highlight the contribution of a secondary factor. After 
filtering out simultaneously the effect of anthropogenic greenhouse gas warming and solar activity variations by a multiple linear regression onto the base-2 logarithm of the Mauna Loa $\mathrm{CO}_{2}$ concentration and Lean's (J. Lean 2000, updated to 2010, personal communication) total solar irradiance (Fig. 4b), the SST skill bears a close resemblance to the one obtained after filtering out the anthropogenic greenhouse gas warming effect only. It appears from this linear approach that the solar activity variations play little role in the Indian Ocean SST skill although some nonlinear effects could have been missed by our methodology. After filtering out simultaneously the effect of anthropogenic greenhouse gas warming and volcanic eruptions (Fig. 4c) by a multiple linear regression onto the base-2 logarithm of the Mauna Loa $\mathrm{CO}_{2}$ concentration and the stratospheric optical thickness at $550 \mathrm{~nm}$ from Sato et al. (1993) [data updated to 2010; M. Sato 2010, personal communication], we observe a strong decrease in the SST correlation skill in the northern part of the basin. The correlation becomes negative in the Seychelles Sea and drops below -0.9 at some points. Only a few points keep a significant correlation. This result suggests a role of the volcanic eruptions on the SST skill in the Indian Ocean that is consistent with Boer et al.'s (2007) results about the regional sensitivity to volcanic eruptions. The remaining significant SST skill could be explained by the role of anthropogenic aerosols but little evidence can be brought up to support this hypothesis at this stage. Furthermore, the initial-condition information might contribute to this remaining skill near Australia and Madagascar as mentioned in the previous section (Fig. 2). Likewise, deviations from the linear approach adopted here may also contribute to this remaining SST skill. After filtering out simultaneously the effect of anthropogenic greenhouse gas warming, volcanic eruptions, and solar activity variations (Fig. 4d), the pattern of remaining SST skill resembles the one obtained after filtering out the effect of anthropogenic greenhouse gas warming and volcanic eruptions only (Fig. 4c), which is consistent with the similarities found between Figs. 4a and 4b. Finally, the same analysis repeated on the CMIP5 NoInit ensemble (Fig. 4e) shows that the remaining SST skill obtained in CMIP5 Init ensemble can be explained to a small extent by the initial-condition information, in particular east of Madagascar, northwest of Australia, and at the southern tip of India. However, most of this remaining skill either originates from the anthropogenic aerosols or stands as an artifact of our linear approach to filter out the various contributions to the varying radiative forcings.

Some more evidence of the role of volcanic eruptions on the Indian Ocean SST skill can be found in Fig. 5, which shows the SST skill of various ensembles after a linear detrend of the SST time series. The spatial patterns of SST skill in the CMIP5 Init ensemble after a linear detrending (Fig. 5a) and after a filtering of the anthropogenic greenhouse gas warming effect by a regression onto the base-2 logarithm of the Mauna Loa concentration (Fig. 4a) exhibit strong similarities. The correlation between those spatial patterns amounts to 0.97 . We thus conclude that linear detrending is a good approximation to filter out the anthropogenic greenhouse gas warming effect for our purpose. The CMIP5 ensemble (Fig. 5a), which comprises the most recent climate models and takes into account the external forcings in the most extensive way (greenhouse gas warming, solar activity, volcanic eruptions, anthropogenic aerosols), has the highest SST skill after a linear detrend. The area-averaged correlation over the $40^{\circ} \mathrm{S}-30^{\circ} \mathrm{N}, 20^{\circ}-120^{\circ} \mathrm{E}$ domain shown in Fig. 5 reaches 0.35 in the CMIP5 ensemble, whereas it reaches only $0.19,-0.01,-0.18$, and 0.03 for the ECMWF Vol, ECMWF NoVol, DePreSys NoVol, and ENSEMBLES NoVol, respectively. The ECMWF set 1 subensemble whose members account for volcanic eruptions (Fig. 5b) has a lower skill than the CMIP5 Init ensemble (Fig. 5a) in the northern part of the Indian Ocean but is still positive. This could be related to the effect of the anthropogenic aerosols that are not accounted for in the ECMWF set 1 ensemble but could also be due to a model-dependent response to the external forcings. Comparing the ECMWF set 1 subensembles that account for the volcanic eruptions (Fig. 5b) or not (Fig. 5d) confirms our previous findings of a significant role of the volcanic eruptions with regard to the SST skill in the northern Indian Ocean. The ensembles that account for the effects of the volcanic eruptions (Figs. 5a,b) have generally much larger SST skill (areaaveraged correlation 0.35 and 0.19 ), especially in the northern Indian Ocean, than the ensembles which do not (Figs. 5c-e, area-averaged correlations $-0.18,-0.01$, and 0.03). A larger SST skill in the northern Indian Ocean is also found by Van Oldenborgh et al. (2012) in the CMIP3 historical simulations that account for the effects of the volcanic eruptions than in those which do not (see their Fig. 6). A puzzling feature is the larger SST skill in the ENSEMBLES (Fig. 5e) and ECMWF set 1 (Figs. 5b,d) ensembles than in the CMIP5 one (Fig. 5a) in the $20^{\circ}-40^{\circ} \mathrm{S}$ latitude band. Neither of those two ensembles takes fully into account the anthropogenic aerosol effects so that this could be associated with a better representation of the internally generated climate component in this area but uninitialized sister experiments would have been necessary to demonstrate this. Furthermore, this remaining SST skill might also originate from model-dependent deviations from the linear response assumed by our methodology. A last comment is 


\section{a) CMIP5 Init Vol}

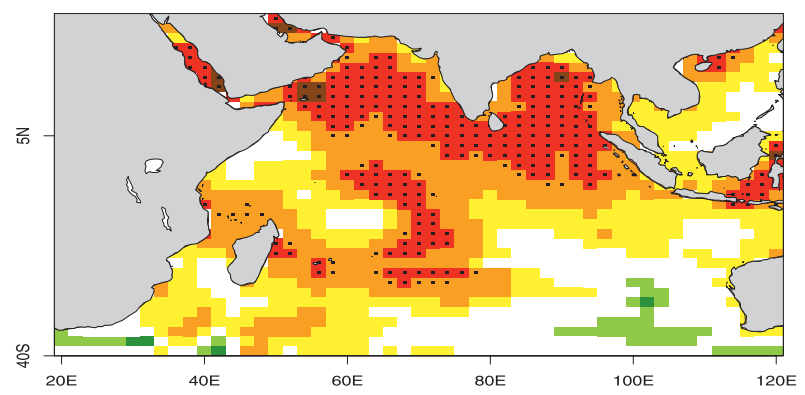

c) DePreSys Init 5y NoVol

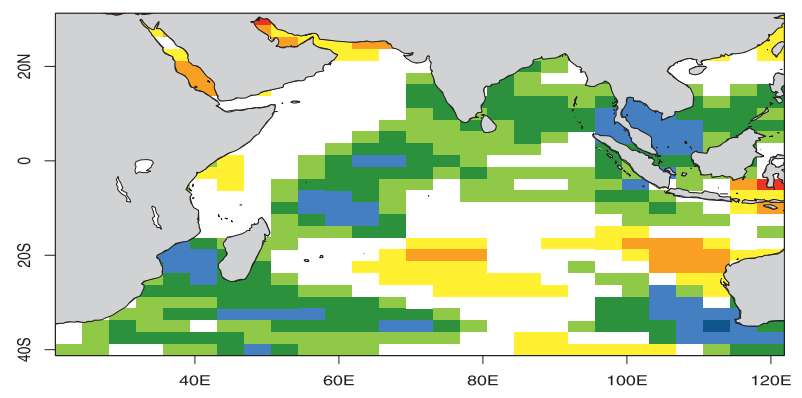

b) ECMWF Init Set1 Vol

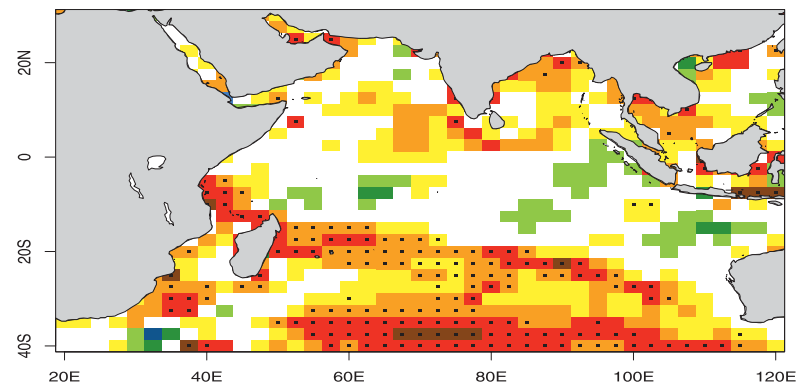

d) ECMWF Init Set1 NoVol

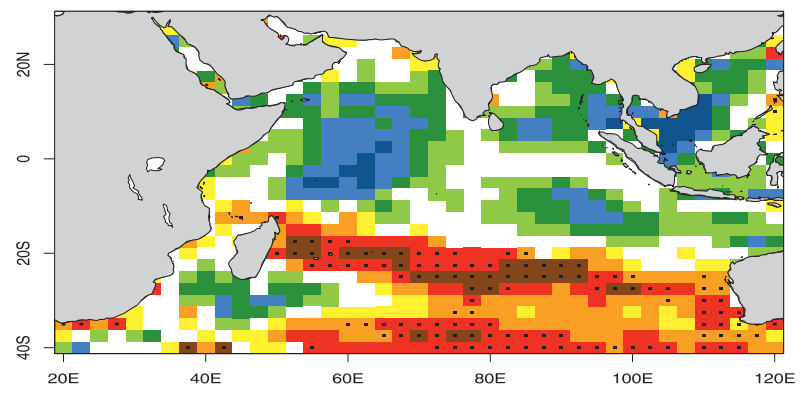

e) ENSEMBLES Init NoVol

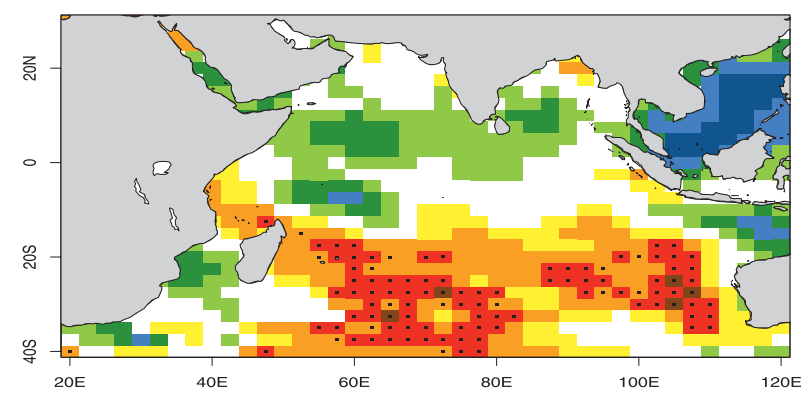

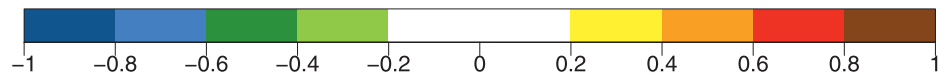

FIG. 5. Correlation between the ensemble-mean predicted and ERSST sea surface temperature anomalies after a linear detrend an$\mathrm{d}$ averaged across the forecast times ranging from 2 to 5 years in (a) the CMIP5 Init multimodel ensemble, (b) the ECMWF Init set 1 members that take into account the volcanic eruptions, (c) the DePreSys Init subensemble with a 5-yr interval between start dates, (d) the ECMWF Init set 1 members that do not account for the volcanic eruptions, and (e) the ENSEMBLES multimodel ensemble. The black dotted regions indicate where the correlation is significant at the $95 \%$ level.

that a comparison of the SST skill in the DePreSys Init hindcasts with yearly start dates (Fig. S5) and with a 5-yr interval between start dates (Fig. 5c) highlights the uncertainty arising from the sampling. This uncertainty stands out as an obstacle to an accurate assessment of the amount of skill that could be related to other factors than the effect of greenhouse gases and volcanic eruptions.

The substantial contribution of the greenhouse warming and volcanic eruptions to the SST skill in the Indian
Ocean can be related to the particularly low relative amplitude of the SST departures from the long-term warming trend and from the volcano-related climate signal compared to the amplitude of those externally forced climate signals themselves, as suggested by Deser et al. (2010a,b) and Boer (2011). Indeed, the Indian Ocean is the region where there appears the largest ratio worldwide (Fig. 6) of the standard deviation of the greenhouse warming and volcanic eruption contributions to the 


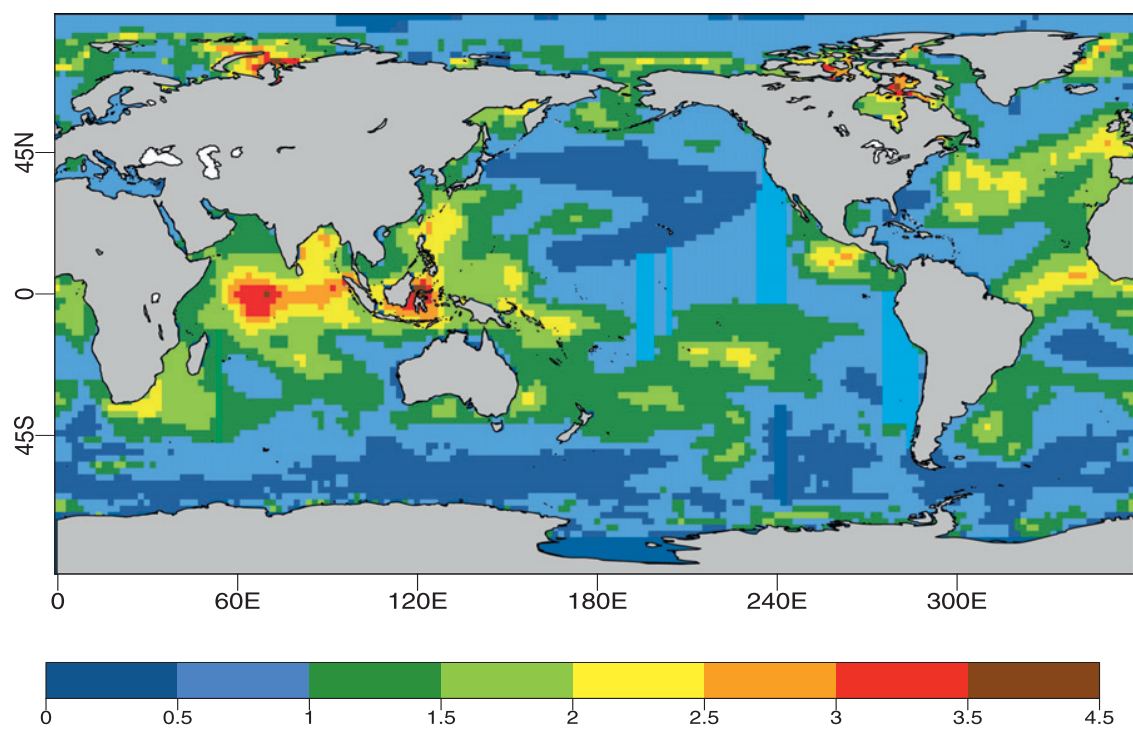

FIG. 6. Ratio of the standard deviation of the contribution by the greenhouse warming and the volcanic eruptions to the ERSST anomalies over the standard deviation of the residuals from those contributions. The contribution of the greenhouse warming and the volcanic eruptions is obtained by a multiple linear regression onto the base- 2 logarithm of the Mauna Loa $\mathrm{CO}_{2}$ concentration and the stratospheric optical thickness at $550 \mathrm{~nm}$ after applying a 48-month running mean. The ratio is computed over the November 1960 to February 2010 period.

observed SST anomalies over the standard deviation of the residuals from those contributions. The contributions of greenhouse warming and volcanic eruptions are estimated by a multiple least squares linear regression of the monthly 4-yr smoothed SST time series onto the base-2 logarithm of the Mauna Loa $\mathrm{CO}_{2}$ concentration and the stratospheric optical thickness at $550 \mathrm{~nm}$. Note, however, that this ratio is lower than 1 northwest of Australia and east of Madagascar, where we hypothesized earlier a nonnegligible contribution of the initialcondition information to the SST skill (Figs. 2 and 4e).

The main results of our study are illustrated in Figs. 7a and $7 \mathrm{~b}$, which show the predicted (in color) and observed (in black) SST anomalies in the Indian Ocean $\left(40^{\circ} \mathrm{S}-30^{\circ} \mathrm{N}, 20^{\circ}-120^{\circ} \mathrm{E}\right)$ averaged across forecast times 2 to 5 years in EC-Earth and DePreSys hindcasts initialized every year (see Fig. S6 for forecast times 6 to 9 years). The observed SST time series can be viewed as a straight warming line onto which are superimposed the cooling associated with the Pinatubo, El Chichón, Fuego, and Agung eruptions respectively in 1991, 1982, 1974, and 1963. The EC-Earth hindcasted SST follows the observed cooling after the Pinatubo, El Chichón, and Fuego eruptions since those effects are prescribed, whereas the DePreSys hindcasted SST follows the warming trend but misses the volcanic eruptions when occurring after the date of initialization. Figure $7 \mathrm{c}$ compares the SST anomalies in the different oceans over the 19602010 period. The root-mean-square differences with the global SST anomalies over the 1970-2010 period are the smallest for the Indian Ocean anomalies. This figure illustrates that the Indian Ocean might not have a larger response to the volcanic eruptions than the well-known global radiative cooling; rather, it has less SST variability other than related to those eruptions. An exception appears in the 1960s when the Indian Ocean cools down more than the other oceans after the Agung eruption. However, this feature is not captured by the EC-Earth yearly hindcasts as can be seen in Fig. 7a, whereas ECEarth seems to represent realistically the effects of the volcanic eruptions in the Indian Ocean. This cooling could then be related to some natural variability that is not captured by the forecast system.

\section{Discussion and conclusions}

In this article, we have used a wide variety of forecast systems to show that the Indian Ocean is the region where the state-of-the-art decadal climate predictions of sea surface temperature (SST) show their best performance worldwide for forecast times ranging from the second to the ninth year, according to correlation and RMSE measures. The climate forecasting community has devoted little attention to this region, probably because of the expected large role of the varying radiative forcing on its skill. However, this premise needs to be tested and the main contributors identified. By comparing CMIP5 and DePreSys decadal hindcasts initialized from 
a) EC-Earth CMIP5 Init

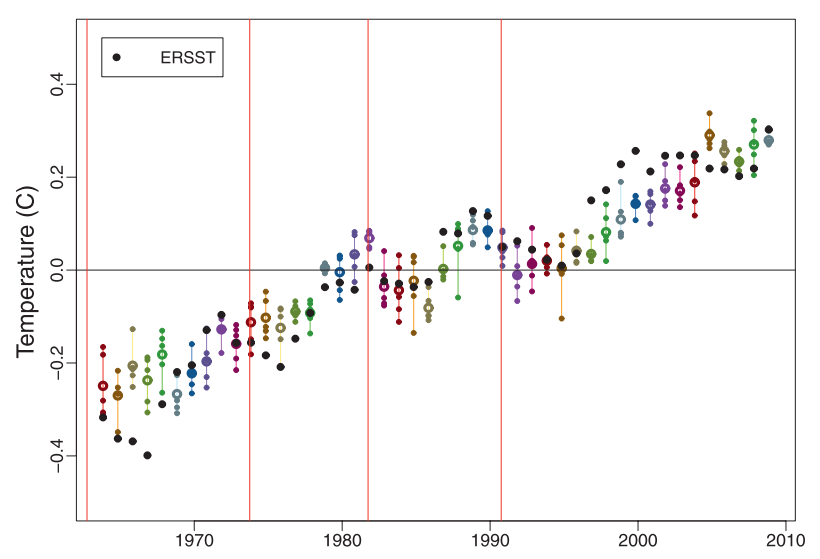

b) DePreSys Init

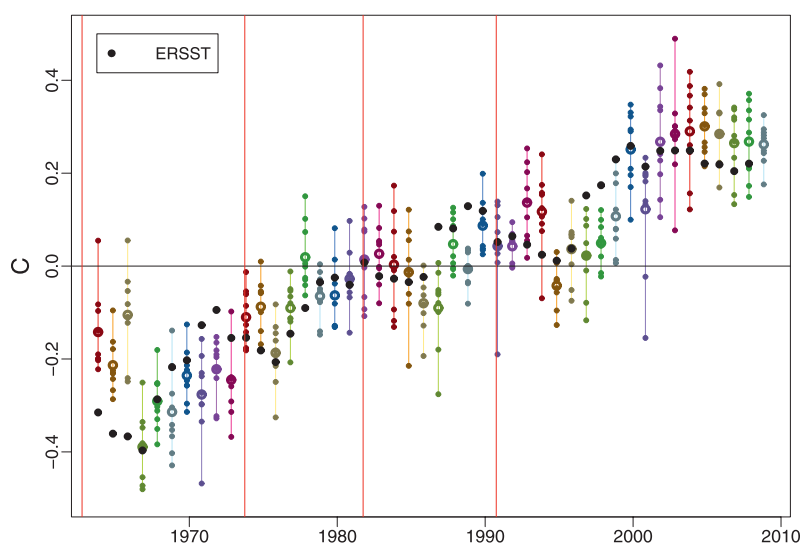

\section{c) Observed SST anomalies per basin}

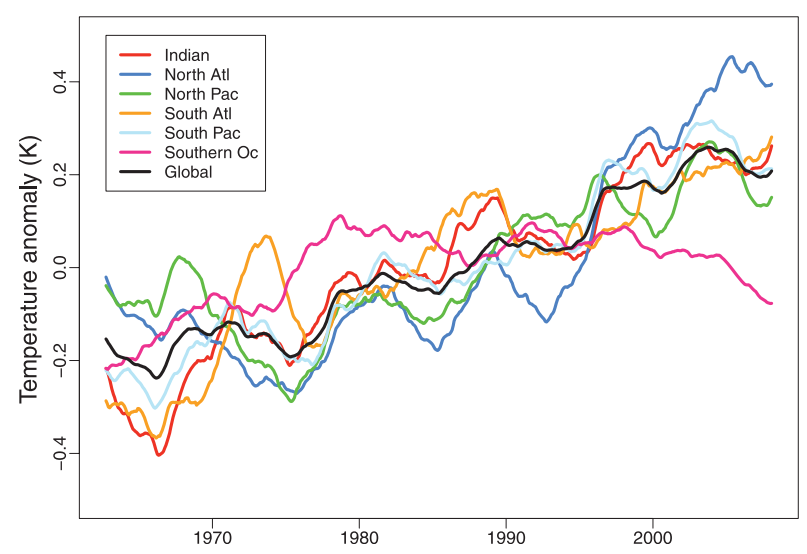

FIG. 7. Per-pair anomalies in SST averaged in the $40^{\circ} \mathrm{S}-30^{\circ} \mathrm{N}, 20^{\circ}-120^{\circ} \mathrm{E}$ box and across the forecast times ranging from 2 to 5 years for (a) the CMIP5 Init EC-Earth decadal hindcasts and (b) the DePreSys Init forecast system. In color: predicted anomalies, one color per start date; the largest dots correspond to the ensemble-mean. In black: observations. Vertical red lines indicate the Pinatubo, El Chichón, Fuego, and Agung eruptions. (c) ERSST anomalies smoothed with a 48-month running mean and averaged over the Indian $\left(40^{\circ} \mathrm{S}-30^{\circ} \mathrm{N}\right.$, $\left.20^{\circ}-120^{\circ} \mathrm{E}\right)$, North Atlantic $\left(0^{\circ}-65^{\circ} \mathrm{N}, 100^{\circ} \mathrm{W}-40^{\circ} \mathrm{E}\right)$, North Pacific $\left(0^{\circ}-65^{\circ} \mathrm{N}, 100^{\circ}-260^{\circ} \mathrm{E}\right)$, South Atlantic $\left(45^{\circ} \mathrm{S}-0^{\circ}, 75^{\circ} \mathrm{W}-20^{\circ} \mathrm{E}\right)$, South Pacific $\left(45^{\circ} \mathrm{S}-0^{\circ}, 120^{\circ}-285^{\circ} \mathrm{E}\right)$, Southern $\left(70^{\circ}-45^{\circ} \mathrm{S}\right)$ and global $\left(60^{\circ} \mathrm{S}-65^{\circ} \mathrm{N}\right)$ oceans.

estimates of the observed climate state with their uninitialized counterpart, we could show that the Indian Ocean high skill can be largely attributed to the effect of the varying radiative forcings. These findings are further illustrated by sensitivity experiments performed with the ECMWF model in which the 1965 and 1995 initial conditions of the hindcasts are substantially modified without any significant effect on the Indian Ocean surface temperature, whereas modifying the external forcings of the hindcasts initialized at the same date has a substantial impact on the surface temperature. Filtering out the effect of the anthropogenic greenhouse gas warming in the CMIP5 hindcasts, we observe a significant remaining
SST skill. This skill is partly attributed to the effect of the volcanic eruptions since filtering out their effect reduces the SST skill in the northern Indian Ocean. These findings are confirmed by a larger SST skill in the northern Indian Ocean in the ECMWF hindcasts that account for the volcanic eruptions than in those that do not. This large contribution of the varying radiative forcings to the Indian Ocean SST skill can be explained by the low relative amplitude of the SST departures from the long-term linear trend and from the volcanorelated climate signal compared to the amplitude of those externally forced climate signals themselves in this region. The substantial impact of volcanic eruptions on 
the Indian Ocean climate stands as an obstacle to skillful operational predictions as those eruptions are not predictable a few years ahead. However, if a volcanic eruption occurs, operational centers would still be able to provide immediately an updated skillful forecast taking into account the new stratospheric conditions. When filtering out the effect of anthropogenic greenhouse gas warming, solar activity variations and volcanic eruptions from CMIP5 initialized hindcasts, a correlation skill above 0.2 remains over one-third of the domain with a few points where this skill is still significant. This could indicate a contribution of the anthropogenic aerosols to the SST skill in the Indian Ocean, supported by the high rate of Asian production (Ramanathan et al. 2007). However, this could also come from inaccuracies in our statistical methods for filtering out the effects of anthropogenic greenhouse gas warming, solar activity variations, and volcanic eruptions, since our approach does not account for the potential nonlinear impact of those forcings. Lengthening the reforecast period would provide a larger set of independent hindcasts and thus allow for robust conclusions regarding the potential role of anthropogenic aerosols on the Indian Ocean SST.

Acknowledgments. Judith Lean, Makiko Sato, and Patrick McCormick are greatly acknowledged for providing the data for total solar irradiance and stratospheric optical thickness at $550 \mathrm{~nm}$. The authors wish to thank the three reviewers for their interesting suggestions. This work was supported by the EU-funded QWeCI (FP7-ENV-2009-1- 243964), CLIM-RUN (FP7-ENV-20101-265192), the MICINN-funded RUCSS (CGL2010-20657) projects, the THOR (FP7/2007-2013) project under grant agreement 212643, the COMBINE (FP7/2007-2013) project under grant agreement 226520, and the Catalan Government. The authors thankfully acknowledge the computer resources, technical expertise, and assistance provided by the Red Española de Supercomputación (RES).

\section{REFERENCES}

Ashok, K., Z. Guan, and T. Yamagata, 2001: Impact of the Indian Ocean dipole on the relationship between the Indian monsoon rainfall and ENSO. Geophys. Res. Lett., 28, 4499-4502.

,,-- and -2003 : Influence of the Indian Ocean dipole on the Australian winter rainfall. Geophys. Res. Lett., 30, 1821, doi:10.1029/2003GL017926.

Bader, J., and M. Latif, 2005: North Atlantic oscillation response to anomalous Indian Ocean SST in a coupled GCM. J. Climate, 18, 5382-5389.

Balmaseda, M. A., K. Mogensen, F. Moteni, and A. Weaver, 2010: The NEMOVAR-COMBINE ocean re-analysis. COMBINE Tech. Rep. 1, 11 pp. [Available online at http://www.combineproject.eu/Technical-Reports.1668.0.html.]
Birkett, C., R. Murtugudde, and T. Allan, 1999: Indian Ocean climate event floods to East Africa's lakes and the Sudd Marsh. Geophys. Res. Lett., 26, 1031-1034.

Boer, G. J., 2011: Decadal potential predictability of twenty-first century climate. Climate Dyn., 36, 1119-1133, doi:10.1007/ s00382-010-0747-9.

—, M. Stowasser, and K. Hamilton, 2007: Inferring climate sensitivity from volcanic events. Climate Dyn., 28, 481-502, doi:10.1007/s00382-006-0193-x.

Dee, D. P., and Coauthors, 2011: The ERA-Interim reanalysis: Configuration and performance of the data assimilation system. Quart. J. Roy. Meteor. Soc., 137, 553-597.

Deser, C., A. Phillips, and M. A. Alexander, 2010a: Twentieth century tropical sea surface temperature trends revisited. Geophys. Res. Lett., 37, L10701, doi:10.1029/2010GL043321.

$\longrightarrow, \ldots$, V. Bourdette, and H. Teng, 2010b: Uncertainty in climate change projections: The role of internal variability. Climate Dyn., 38, 527-546, doi:10.1007/s00382-010-0977-x.

Doblas-Reyes, F. J., A. Weisheimer, T. N. Palmer, J. M. Murphy, and D. Smith, 2010: Forecast quality assessment of the ENSEMBLES seasonal-to-decadal stream 2 hindcasts. ECMWF Tech. Memo. 621, 45 pp.

_ M. A. Balmaseda, A. Weisheimer, and T. N. Palmer, 2011: Decadal climate prediction with the European Centre for Medium-Range Weather Forecasts coupled forecast system: Impact of ocean observations. J. Geophys. Res., 116, D19111, doi:10.1029/2010JD015394.

Du, H., F. J. Doblas-Reyes, J. Garcia-Serrano, V. Guemas, Y. Soufflet, and B. Wouters, 2012: Sensitivity of decadal predictions to the initial atmospheric and oceanic perturbations. Climate Dyn., 39, 2013-2023.

Fichefet, T., and M. A. M. Maqueda, 1997: Sensitivity of a global sea ice model to the treatment of ice thermodynamics and dynamics. J. Geophys. Res., 102 (C6), 12 609-12 646.

Garcia-Serrano, J., and F. J. Doblas-Reyes, 2012: On the assessment of near-surface global temperature and North Atlantic multi-decadal variability in the ENSEMBLES decadal hindcast. Climate Dyn., 39, 2025-2040.

Goosse, H., and T. Fichefet, 1999: Importance of ice-ocean interactions for the global ocean circulation: A model study. J. Geophys. Res., 104 (C10), 23 337-23 355.

Gordon, C., C. Cooper, C. Senior, H. Banks, J. Gregory, T. Johns, J. Mithell, and R. Wood, 2000: The simulation of SST, sea ice extents and ocean heat transports in a version of the Hadley Center coupled model without flux adjustments. Climate Dyn., 16, 147-168.

Hasumi, H., and S. Emori, 2004: K-1 coupled GCM (MIROC) description. K-1 Tech. Rep. 1, Center for Climate System Research, University of Tokyo, $34 \mathrm{pp}$.

Hawkins, E., and R. Sutton, 2009a: Decadal predictability of the Atlantic Ocean in a coupled GCM: Forecast skill and optimal perturbations using linear inverse modeling. J. Climate, 22, 3960-3978.

$\longrightarrow$, and $-2009 \mathrm{~b}$ : The potential to narrow uncertainty in regional climate predictions. Bull. Amer. Meteor. Soc., 90, 1095-1107.

Hazeleger, W., and Coauthors, 2010: EC-Earth: A seamless Earthsystem prediction approach in action. Bull. Amer. Meteor. Soc., 91, 1357-1363.

Hoerling, M. P., J. W. Hurrell, and T. Xu, 2001: Tropical origins for recent North Atlantic climate change. Science, 292, 90-92, doi:10.1126/science.1058582.

Keenlyside, N. S., M. Latif, J. Jungclaus, L. Kornblueh, and E. Roeckner, 2008: Advancing decadal-scale climate prediction 
in the North Atlantic sector. Nature, 453, 84-88, doi:10.1038/ nature 06921 .

Madec, G., 2008: NEMO ocean engine. Note du Pôle de modélisation No. 27, Institut Pierre-Simon Laplace, 367 pp.

Magnusson, L., M. A. Balmaseda, and F. Molteni, 2011: On the dependence of ENSO simulation on the coupled model mean state. ECMWF Tech. Memo. 658, 27 pp.

Meehl, G. A., and Coauthors, 2009: Decadal prediction. Bull. Amer. Meteor. Soc., 90, 1467-1485.

Mochizuki, T., and Coauthors, 2010: Pacific decadal oscillation hindcasts relevant to near-term climate prediction. Proc. Natl. Acad. Sci. USA, 107, 1833-1837, doi:10.1073/pnas.0906531107.

Molteni, F., and Coauthors, 2011: The new ECMWF seasonal forecast system (system 4). ECMWF Tech. Memo. 656, 49 pp.

Murphy, J., D. Sexton, D. Barnett, G. Jones, M. Webb, M. Collins, and D. Stainforth, 2004: Quantification of modelling uncertainties in a large ensemble of climate change simulations. Nature, 430, 768-772.

— variability and change. Procedia Environ. Sci., 1, 287-304.

Pohlmann, H., J. H. Jungclaus, A. Kohl, D. Stammer, and J. Marotzke, 2009: Initializing decadal climate predictions with the GECCO oceanic synthesis: Effects on the North Atlantic. J. Climate, 22, 3926-3938.

Pope, V. D., M. L. Gallani, P. R. Rowntree, and R. A. Stratton, 2000: The impact of new physical parametrizations in the Hadley Centre climate model-HadAM3. Climate Dyn., 16, 123-146, doi:10.1007/s003820050009.

Ramanathan, V., M. V. Ramana, G. Roberts, D. Kim, C. Corrigan, C. Chung, and D. Winke, 2007: Warming trends in Asia amplified by brown cloud solar absorption. Nature, 448, 575-578.

Robson, J., 2010: Understanding the performance of a decadal prediction system. Ph.D. dissertation, University of Reading, 133 pp.

Saji, N. H., B. N. Goswami, P. N. Vinayachandran, and T. Yamagata, 1999: A dipole mode in the tropical Indian Ocean. Nature, 401, 360-363.

Sanchez-Gomez, E., C. Cassou, D. L. R. Hodson, N. Keenlyside, Y. Okumura, and T. Zhou, 2008: North Atlantic weather regimes response to Indian-western Pacific Ocean warming:
A multi-model study. Geophys. Res. Lett., 35, L15706, doi:10.1029/2008GL034345.

Sato, M., J. E. Hansen, M. P. McCormick, and J. B. Pollack, 1993: Stratospheric aerosol optical depths, 1850-1990. J. Geophys. Res., 98 (D12), 22 987-22 994.

Smith, D. M., A. Cusack, A. Colman, C. Folland, G. Harris, and J. M. Murphy, 2007: Improved surface temperature prediction for the coming decade from a global climate model. Science, 317, 796-799, doi:10.1126/science.1139540.

R. Eade, N. J. Dunstone, D. Fereday, J. M. Murphy, H. Pohlmann, and A. A. Scaife, 2010: Skilful multi-year predictions of Atlantic hurricane frequency. Nat. Geosci., 3, 846-849.

Smith, I. N., P. McIntosh, T. Ansell, C. J. C. Reason, and K. McInnes, 2000: Southwest Western Australian winter rainfall and its association with Indian Ocean climate variability. Int. J. Climatol., 20, 1913-1930.

Smith, T. M., R. W. Reynolds, T. C. Peterson, and J. Lawrimore, 2008: Improvements to NOAA's historical merged landocean surface temperature analysis (1880-2006). J. Climate, 21, 2283-2296.

Taylor, K. E., R. J. Stouffer, and G. A. Meehl, 2011: An overview of CMIP5 and the experimental design. Bull. Amer. Meteor. Soc., 93, 485-498.

Uppala, S., and Coauthors, 2004: ERA-40: ECMWF 45-year reanalysis of the global atmosphere and surface conditions 19572000. ECMWF Newsletter, No. 101, ECMWF, Reading, United Kingdom, 2-21.

Van Oldenborgh, G. J., F. J. Doblas-Reyes, B. Wouters, and W. Hazeleger, 2012: Decadal prediction skill in a multi-model ensemble. Climate Dyn., 38, 1263-1280, doi:10.1007/s00382012-1313-4.

VonStorch, H., and F. W. Zwiers, 1999: Statistical Analysis in Climate Research. Cambridge University Press, 494 pp.

Yukimoto, S., and Coauthors, 2001: The New Meteorological Research Institute coupled GCM (MRI-CGCM2) model climate and variability. Pap. Meteor. Geophys., 51, 47-88.

Zieba, A., 1995: Effective number of observations and unbiased estimators of variance for autocorrelated data-An overview. Metrol. Meas. Syst., 17, 3-16. 